\title{
Effect of high thermal expansion glass infiltration on mechanical properties of alumina-zirconia composite
}

\author{
A BALAKRISHNAN ${ }^{\dagger}$, B B PANIGRAHI, K P SANOSH ${ }^{\dagger}$, MIN-CHEOL CHU, \\ T N KIM ${ }^{\dagger}$ and SEONG-JAI CHO* \\ Division of Metrology for Emerging Technology, Korea Research Institute of Standards and Science, \\ 1 Doryong-Dong, Yuseong-Gu, Daejeon 305-340, Republic of Korea \\ ${ }^{\dagger}$ Department of Information and Electronic Materials Engineering, College of Engineering, Paichai University, \\ Daejeon 302-735, Republic of Korea
}

MS received 27 July 2008; revised 28 August 2008

\begin{abstract}
This work studies the effect on the mechanical properties of alumina-10 wt\% zirconia (3 mol\% yttria stabilized) composite by infiltrating glass of a higher thermal expansion (soda lime glass) on the surface at high temperature. The glass improved the strength of composite at room temperature as well as at high temperature. This could be attributed to the drastic drop in the coefficient of thermal expansion due to the compositional change in the soda lime glass during infiltration. There was a significant improvement in the Weibull modulus after glass infiltration. Glass infiltrated samples showed better thermal shock resistance. The magnitude of strength increment was found to be in the order of the surface residual stress generated by thermo-elastic properties mismatch between the composite and the penetrated glass.
\end{abstract}

Keywords. Infiltration; thermal expansion; compressive stress; strength; thermal shock; ZTA.

\section{Introduction}

The strengthening of polycrystalline ceramics has been a topic of interest among the ceramists over the past few decades. Whiskers (or particles) reinforcing, phase transformation and surface residual compression strengthening have been shown to improve the mechanical properties of ceramics (Lange 1982; Virkar 1987; Virkar et al 1987; Lin et al 1993). The interest in the surface compression method is for two reasons: firstly, the residual stresses impose additional stresses in the ceramic thereby improving the strength and secondly, the compressive residual stress leads to crack closure and delays crack propagation (ASM International 1991; Wulf and Rombach 1999) which enhances the service behaviour of the machined parts significantly. Various techniques are applied for inducing surface compression such as quenching treatments, coating of a lower expansion materials, phase transformation (to a larger volume phase), ion exchange technique, chemical strengthening (deposition of low expansion coatings on the surface by chemical reaction with suitable elements and compounds), grinding, grid blasting and shot peening techniques, etc (Kirchner et al 1968, 1971; Kirchner 1979; Swain 1980; Marple and

*Author for correspondence

(the_krecian@yahoo.com, sjcho@kriss.re.kr)
Green 1988; Kishino et al 1996; Chakraverty and Rice 1997; Lin and Virkar 2001; Wulf and Tobias 2002, 2006). However, techniques like machining, grinding, grid blasting and shot peening procedures affect the precision, surface finish and can initiate surface flaws (Wulf and Tobias 2002). The chemical strengthening or the diffusion based process leads to grain coarsening over a longer treatment time and thereby deteriorates the property. Ion exchange method causes a compositional gradient and stress variation in the coating. Moreover, achieving a compressive layer over a depth of strength controlling flaws (typically of the order of $\sim 200 \mu \mathrm{m}$ ) is difficult by above techniques. Our previous works showed that by infiltrating a low expansion glass (Guazzato et al 2005; Hua et al 2003; Xiang et al 2004; Magdalena and Marek 2006; Chu et al 2007; Balakrishnan et al 2007) on the surface of ceramics, significant increment in room and high temperature strength, thermal shock resistance and reliability could be achieved. This technique could produce compressive stress in the layers much deeper than the depth of the strength controlling flaws and can enhance the strength of ceramics by about 25$50 \%$. This was attributed to the presence of residual compression arising between the glass phases and surrounding matrix during the infiltration. In the present investigation, we used a lower expansion substrate, zirconia toughened alumina (ZTA) (zirconia-3 mol\% yttria stabilized) and infiltrated it with higher expansion soda 
lime glass. It was expected that the reverse effect of infiltrating high expansion glass on the lower thermal expansion ZTA would induce tensile stress on the surface which in turn would deteriorate the mechanical properties of the ceramic. Contradictory to the expectations, an enhancement in mechanical properties was observed. Hence, efforts were made to understand this strengthening behaviour of ZTA by using soda lime (SL) glass. The high temperature flexural strength and the thermal shock resistant properties have also been evaluated. The surface stresses generated during glass infiltration have been characterized experimentally as well as theoretically.

\section{Experimental}

ZTA was prepared by mixing fine powders of zirconia$3 \mathrm{~mol} \%$ yttria stabilized (NL-3 YZ, NamoLab, Korea) and alumina (doped with $0.1 \mathrm{wt} \% \mathrm{MgO}, \mathrm{AES}-11$, Sumitomo Chemicals, Japan) in the ratio (weight) of $1: 9$. This powder was centrifugally cast into tubes and sintered at $1600^{\circ} \mathrm{C}$ for $2 \mathrm{~h}$ (theoretical density of $\sim 99.0 \%$ ). Table 1 summarizes the properties of sintered ZTA and glasses used for this study. Flat specimens $(3 \times 40 \times 40 \mathrm{~mm})$ of ZTA were prepared. The glasses were finely ground and sieved under -200 mesh size. Slurry made of fine powdered glass and ethanol was uniformly pasted on the $40 \times 40 \mathrm{~mm}$ surface of the flexural specimens. The glass pasted side of the specimen was kept in an upward direction and heated in an electric furnace (Daesung, Korea) at $1500^{\circ} \mathrm{C}$ in air for different isothermal periods of 30,60 , 120 and $300 \mathrm{~min}$. The SL glass treated specimens were designated as ZS30, ZS60, ZS120 and ZS300 for the holding time of $30,60,120$ and $300 \mathrm{~min}$, respectively. The glass treated specimen surface was ground with a resin bonded diamond wheel (EHWA TC800, GRIT, Korea) to remove the extra glass. Flexural specimens $(3 \times 4 \times 40 \mathrm{~mm})$ of both sintered and SL glass treated ZTA were made as per ISO specification (ISO 14704 2000). Twenty specimens were tested for each condition (holding time). Flexural test (four-point) were carried out with an Instron 4465, USA with $\mathrm{SiC}$ fixture, having outer and inner spans of $30 \mathrm{~mm}$ and $10 \mathrm{~mm}$, respectively. The glass treated surface was kept in tension mode. The crosshead speed for the strength measurements was $0.5 \mathrm{~mm} /$ $\min$.
The broken specimens were polished along the crosssection and etched thermally at $1500^{\circ} \mathrm{C}$ for $1 \mathrm{~h}$ in case of sintered ZTA to reveal grain boundaries. The polished cross-section of glass treated specimens was etched chemically in $60 \% \mathrm{HF}$ for $3 \mathrm{~min}$ to determine the glass penetration depth. The microstructure and elemental composition of the phase of the specimen was analysed using scanning electron microscope-energy dispersive X-ray (SEM-EDX, ISI-DS130C dual stage SEM, Akashi, Japan). The presence of the crystalline phases was determined using X-ray diffractometer (Rigaku, Geiger Flex, Japan).

Further evaluation of mechanical properties and characterization of residual stress were carried out on the optimized specimens with highest strength. Procedure similar to the room temperature flexural test was followed for the high temperature tests also at $500^{\circ} \mathrm{C}$ and $700^{\circ} \mathrm{C}$ heated with a heating rate of $10^{\circ} \mathrm{C} / \mathrm{min}$ in air using Instron 8562. There was no sign of sticking or wetting of glass on the SiC fixtures during tests. Thermal shock tests were carried out in a vertical tubular furnace (Daesung, Korea) over a range of temperatures $\left(100-450^{\circ} \mathrm{C}\right)$. The specimens were suspended with the help of a thin platinum wire and quenched by dropping through the bottom opening of the furnace into a water filled container $\left(\sim 23^{\circ} \mathrm{C}\right)$. For each sample this procedure was repeated for three thermal cycles. The samples were tested for the flexural strength at room temperature. Five specimens for each system were used for the above experiments. The surface stress of the glass treated specimen was analysed using the following techniques.

\subsection{XRD technique}

The XRD patterns were obtained using $\mathrm{Cu}(\lambda=1.5206 \AA)$ on the surface of as-sintered ZTA and glass penetrated ZTA. The residual stress from the high angle peak shifts was quantified using low incident beam angle diffraction (LIBAD) method (Van Acker et al 1994).

\subsection{Indentation technique}

The Vickers indentations on the glass penetrated surface were made using Matsuzawa DVK-25, indenter (Japan) at

Table 1. Properties of ZTA and glass.

\begin{tabular}{lccc}
\hline $\begin{array}{l}\text { Properties } \rightarrow \\
\text { Materials } \downarrow\end{array}$ & $E(\mathrm{GPa})$ & Poisson's ratio $(v)$ & $\mathrm{CTE}\left({ }^{\circ} \mathrm{C}\right)$ \\
\hline ZTA & & & \\
SLG & 310 & $0 \cdot 26$ & $8.4 \times 10^{-6 *}$ \\
Penetrated SLG & 75 & $0 \cdot 17$ & $9 \times 10^{-6 *}, 8.7 \times 10^{-6 \dagger}$ \\
\hline
\end{tabular}

*Experimentally determined value, ${ }^{\dagger}$ theoretically calculated using Appen's model (Volf 1988) 
a load of $49 \mathrm{~N}$. One medium load of $49 \mathrm{~N}$ was preferred to prevent the extensive chipping or spalling due to lateral cracks intersecting the surface of specimen at higher loads (Marshall and Lawn 1977; Swain et al 1977; Tandon et al 1977). The crack lengths on the sample were measured immediately after the indentation. The difference in crack lengths of the sintered ZTA and glass penetrated ZTA was used to determine the surface stress (Marshall and Lawn 1977). By assuming that the residual stress is constant at the entire crack front and the indentation crack is in half penny shape, the stress on the surface can be obtained by (Marshall and Lawn 1977)

$$
\sigma_{\text {indentation }}=\frac{1}{1 \cdot 12 C_{\mathrm{R}}^{1 / 2}}\left(\frac{\beta P}{C_{\mathrm{R}}^{3 / 2}}-\frac{\beta P}{C_{0}^{3 / 2}}\right)
$$

where $\sigma_{\text {indentation }}$ is the surface stress, $\beta$ the dimensionless constant incorporating details of indenter/specimen contact, $P$ the indenter load, $C_{\mathrm{R}}$ and $C_{0}$ are the crack length on the glass penetrated ZTA and sintered ZTA, respectively.

\subsection{Strain gauge method}

The strain in the sample was measured using strain gauge (Tokyo Sokki Kenkyuja Co., Ltd) as a function of removal depth. The strain gauge was connected to a multichannel data logger (UCAM-70A, Kyowa, Japan) which was used to record the micro-strain data along the surface. The glass penetrated region was removed layer by layer uniformly along the length using the resin bonded diamond wheel. The stress profile was calculated using Virkar's (1990) model.

\section{Results and discussion}

Figure 1a shows the SEM microstructure of as-sintered ZTA. Some pores were observed at triple grain junctions and zirconia particles were distributed fairly along the alumina matrix. Figure $1 \mathrm{~b}$ shows the cross-sectional views of the surface region of glass penetrated samples with the extra glass remaining on the surface. The surface region contained a glassy phase (darker area) between ZTA matrix. Glass filled the pores at triple grain junctions as expected. The alumina grains seem to lose the distinct feature of interconnected grain boundaries and sharp corners. The presence of glass tends to spheroidize the faceted alumina grains. The spheroidization and surface smoothening of the grains in presence of liquid by lowering its energy was reported in ceramics (Park et al 1986; Ramamurthy et al 1996). The glass infiltrated samples showed dispersed zirconia phase on the extra glass, indicating that zirconia was not only dissolving at high temperature, but also re-precipitating during cooling (figure 1(c)). The dissolution and re-precipitation of zirconia in glass penetrated samples indicated a possible compositional change in the penetrated glass. It is difficult to accurately determine, how much zirconia and/or alumina dissolved in the glass. Attempt to determine composition of the penetrated glass using oxides of elements detected by EDX analysis, led to recording of highly exaggerated and erroneous values of $\mathrm{Al}$ and $\mathrm{Zr}$ from the neighbouring matrix and also from the grains below the glassy phase, because of the beam spreading problem (Goldstein et al 2003). Hence, an independent EDX analysis of the extra surface glass was done at sufficient distance from the ZTA matrix. Figure 2 shows EDX analysis of SL glass both before and after penetration. The SL glass showed high amounts of $\mathrm{Al}$ and $\mathrm{Zr}$ elements after penetrations, which were not present in the initial glass. This change in composition did not vary much over the period of holding time (after $60 \mathrm{~min}$ ), possibly due to saturation. The glass penetration depth (figure 3) increased with increasing holding time.

Flexural tests (figure 4) showed the average strength of as-sintered ZTA to be about $456 \pm 52 \mathrm{MPa}$. This average strength value was in proximity to the value of $450 \mathrm{MPa}$ reported for sintered ZTA (ASM International 1991). The strength of glass-penetrated ZTA increased by about $192 \mathrm{MPa}(\sim 42 \%)$ for ZS120. ZS120 samples were chosen for further characterization and mechanical properties evaluation.

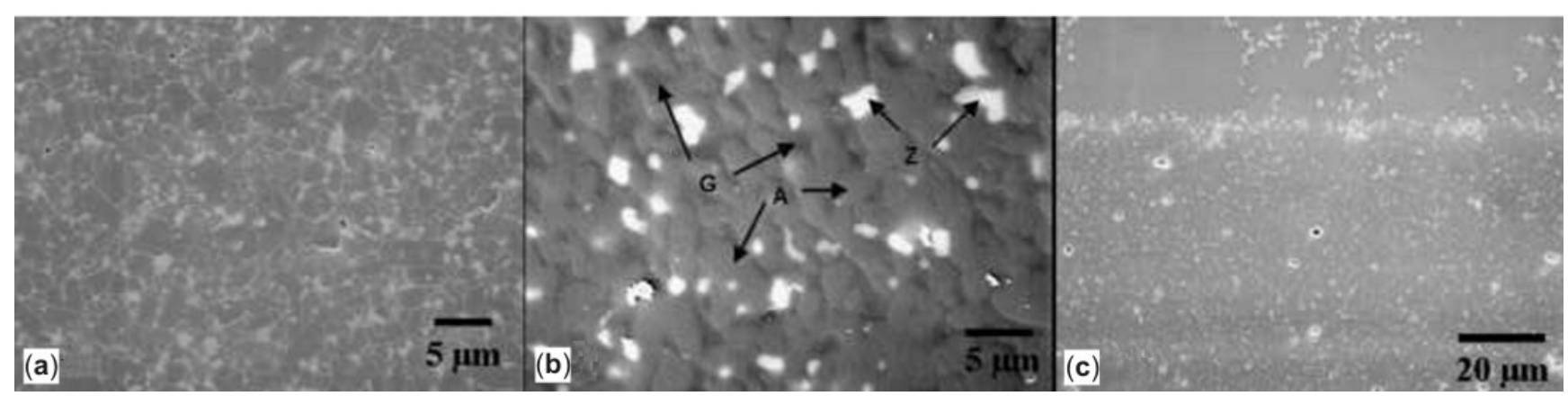

Figure 1. SEM images of (a) as-sintered ZTA with uniformly dispersed zirconia (white) in alumina (grey) matrix, (b) SL glass (dark grey phase) penetrated in ZTA and (c) dissolution and re-precipitation of zirconia from ZTA matrix to extra glass. 

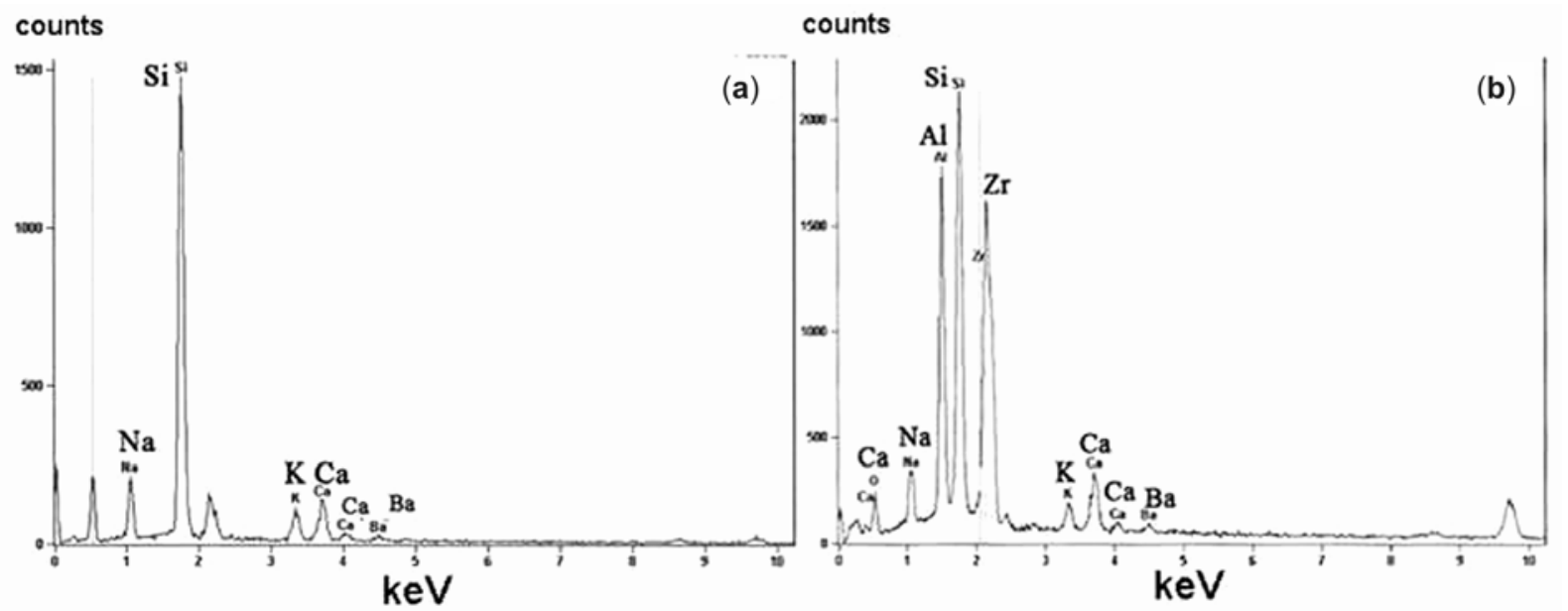

Figure 2. EDX analysis of SL glass (a) before and (b) after glass penetration.

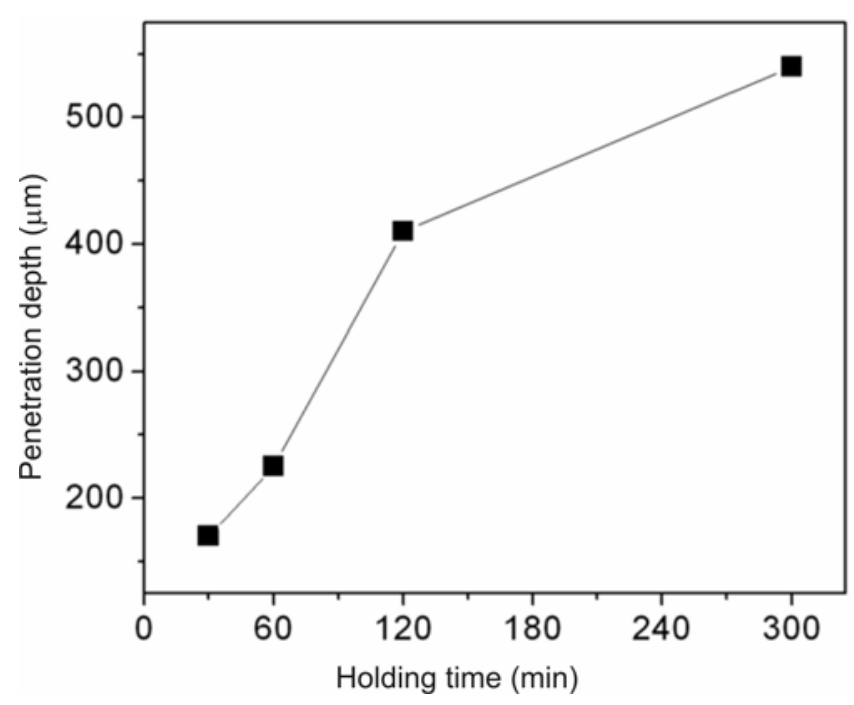

Figure 3. Glass penetration depth as a function of holding time.

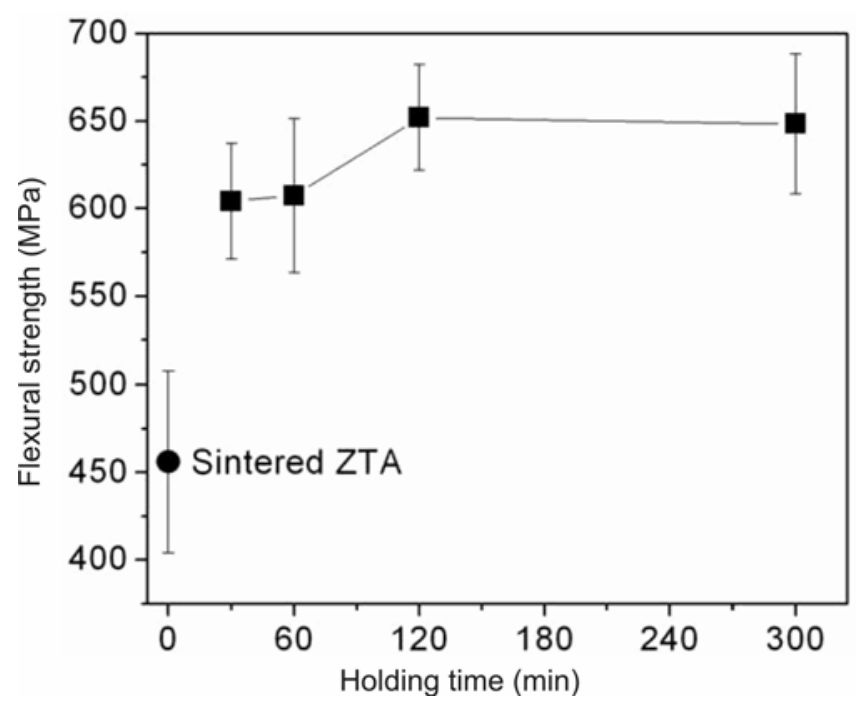

Figure 4. Variation of room temperature flexural strength as a function of holding time.
In ZS120 samples, the XRD peaks (corresponding to $\alpha$-alumina) shifted towards lower angles compared to that of ZTA sample (figure 5) indicating an increase in the inter-planar spacing in the direction normal to the surface. This could be due to the compressive residual stresses acting in the direction parallel to the surface. Due to very low intensities of high angle peaks, zirconia peaks were not considered for stress analysis. Since the $E$ and $v$ values for specific planes are not readily available, the compressive stress values obtained by these peak shifts were quantified using the properties of polycrystalline ZTA (table 2). No crystalline peaks other than that of zirconia and alumina were detected during XRD.

Strain gauge (figure 6) revealed decreasing compressive stress as the glass penetrated region was removed incrementally. When the glass penetrated region was removed completely, the samples showed complete removal of residual compression, however, little amounts of tensile stresses could be seen beyond glass penetration depth.

During the indentation, the crack lengths were much smaller in case of ZS120 specimen compared to ZTA, confirming the presence of compression stress in the glass treated samples. Measured stresses by this method have been shown in table 2 .

It is expected that compositional changes during penetration would alter the CTE value of glass. However, it is difficult to determine CTE of the penetrated glass. Model given by Appen (Volf 1988) based on the dependency of CTE on the compositional change, shows that inclusion of zirconia and alumina in glass phase in fact reduces the CTE of penetrated SL glass. The effectiveness of this model was verified by determining the CTE value of the starting composition of SL glass, which was in close proximity to the experimentally determined values. The CTE of the penetrated SL glass calculated using Appen's model showed significantly lower values than the CTE of the starting SL glass (table 1). 
Based on the parameters given in table 1 , an effort was made to calculate the surface residual stress for thermoelastic mismatch using the procedure explained in the earlier work (Chu et al 2007). The glass treated sample was assumed as a bi-layer system, having a coating of ZTA-glass composite on ZTA substrate. The stresses on the coating during cooling can be generated from two major sources: (a) the stress $\left(\sigma_{\mathrm{m}}\right)$ due to the thermal and elastic properties mismatch between the glass and the ZTA within the composite film (stress is assumed to be equal in all directions) and (b) the stress $\left(\sigma_{\mathrm{f}}\right)$ due to the thermal and the elastic properties mismatch between the composite film and the ZTA substrate (which is biaxial in nature). If the two principal stresses are equal, the uniaxial component $\left(\sigma_{1}\right)$ of $\sigma_{\mathrm{f}}$ would be approximately $\sigma_{\mathrm{f}} / 2$. The net stress on the glass treated ZTA surface can be given by $\sigma_{\text {thermal }}=\sigma_{\mathrm{m}}+\left(\sigma_{\mathrm{f}} / 2\right)$. In addition, the stress can also be developed due to the tetragonal to the monoclinic phase transformation of zirconia; however, this effect is expected to be identical in both, ZTA and glass-treated ZTA systems.

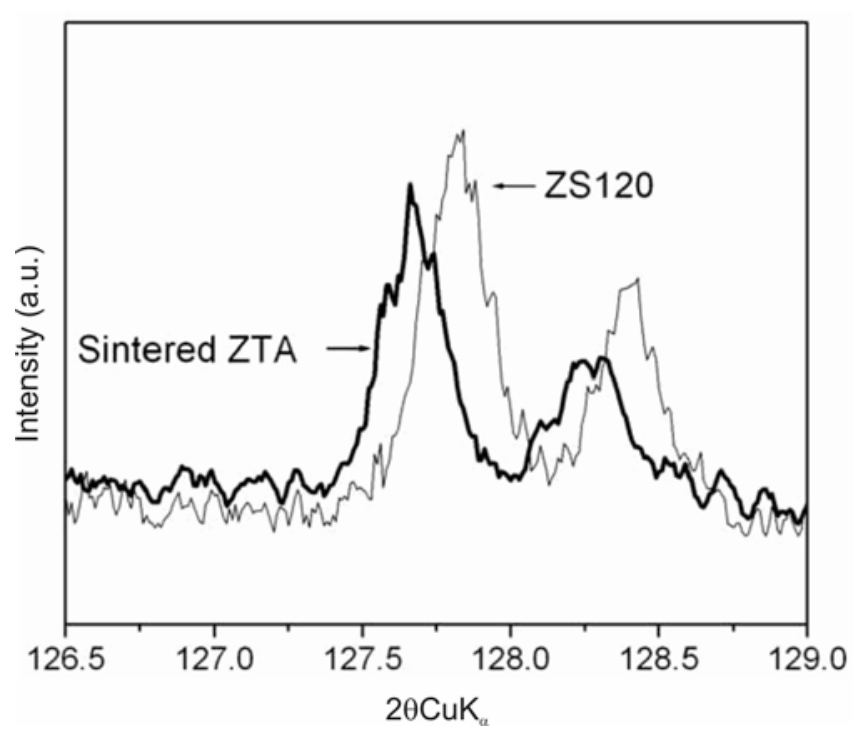

Figure 5. X-ray diffraction patterns of ZTA and ZS120 samples.

Table 2. Comparison of measured surface stress and predicted stress.

\begin{tabular}{|c|c|}
\hline $\begin{array}{l}\text { Samples } \rightarrow \\
\text { Method } \downarrow\end{array}$ & $\begin{array}{l}\text { ZS120 sample } \\
\text { Stress (MPa) }\end{array}$ \\
\hline $\begin{array}{l}\text { Increment of average strength } \\
\text { Vickers indentation } \\
\text { XRD } \\
\text { Strain gauge } \\
\text { Predicted stress }\end{array}$ & $\begin{array}{l}196 \\
\sigma_{\text {indentation-zs }}=-(265 \pm 58) \\
\sigma_{\text {XRD-zs }}=-(227 \pm 55) \\
\sigma_{\text {sgauge-zs }}=-(246 \pm 65) \\
\sigma_{\text {thermal-zs } 1}=+18^{\dagger} \\
\sigma_{\text {thermal-zs } 2}=-164^{\ddagger}\end{array}$ \\
\hline
\end{tabular}

'-' compressive, '+' tensile, ${ }^{\dagger}$ calculations based on CTE and E value of ZTA and initial SL glass, ${ }^{\ddagger}$ calculations based on CTE and $\mathrm{E}$ value of ZTA and penetrated SL glass
The measured ( $\sigma_{\text {indentation}}, \sigma_{\mathrm{XRD}}$, and $\left.\sigma_{\text {sgauge }}\right)$ and the predicted surface stress ( $\left.\sigma_{\text {thermal }}\right)$ values have been shown in table 2 . When the stress $\left(\sigma_{\text {thermal-zsl }}\right)$ was predicted by using the CTE value of starting SL glass, it yielded a tensile stress of very low magnitude (table 2 ). The predicted surface stress $\left(\sigma_{\text {thermal-zs } 2}\right)$ for ZS120 sample while using the CTE of the penetrated SL glass (derived from Appen's model) and assuming that the $E$ and $v$ values of the glass remained unchanged, showed a high amount of compressive stress. The predicted surface stresses for ZS120 samples have been found to have values relatively smaller than their respective surface stresses measured experimentally. However, the magnitudes of predicted stresses matched closely with the observed strength increment. All the measurement techniques confirmed that the surface stress in ZS120 sample was compressive in nature.

The thermal shock (figure 7) tests revealed that the critical quenching temperature required for the cracking and thus abrupt decrease of strength, increased from $\sim 230^{\circ} \mathrm{C}$ for as sintered ZTA to $\sim 310^{\circ} \mathrm{C}$ for ZS120 samples. The increased thermal shock resistance could be attributed to the compressive glass-ZTA composite layer, which acts as a protective layer, having lower elastic modulus and less brittle in nature compared to ZTA.

The samples with compressive stress (glass treated samples) performed better than the stress free samples of ZTA during high temperature flexural test. ZS120 specimen exhibited significantly higher strength compared to both, ZTA at 500 and $700^{\circ} \mathrm{C}$ (figure 8).

The reliability of the room temperature strength was evaluated by the Weibull statistics analysis. Glass treated samples showed high Weibull modulus values (figure 9), which could be attributed to the removal of defects or pores in surface region and the presence of compressive

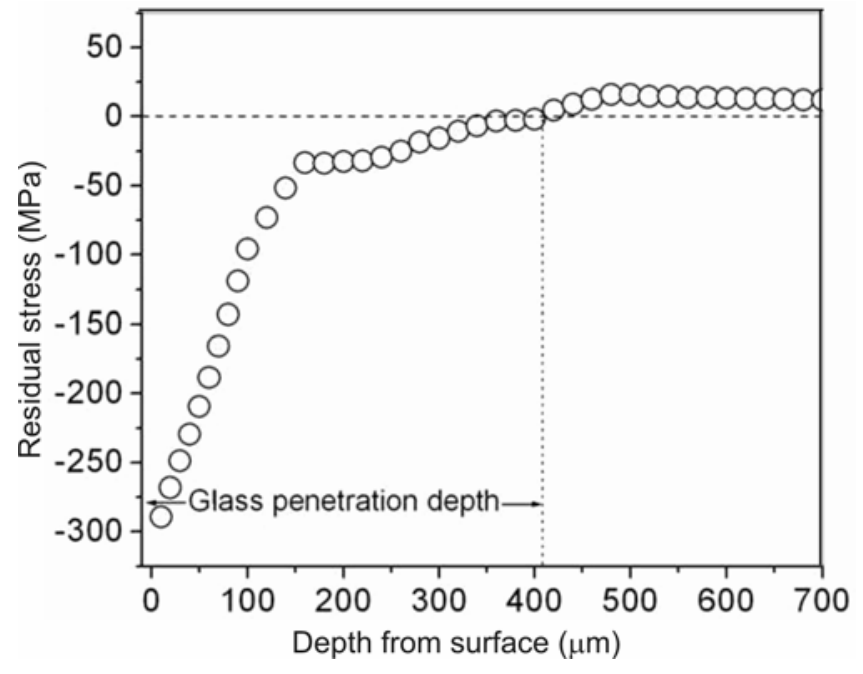

Figure 6. Stress profile of ZS120 samples as a function of thickness (removed layer by layer from the surface), obtained from the strain data (using strain gauge). 


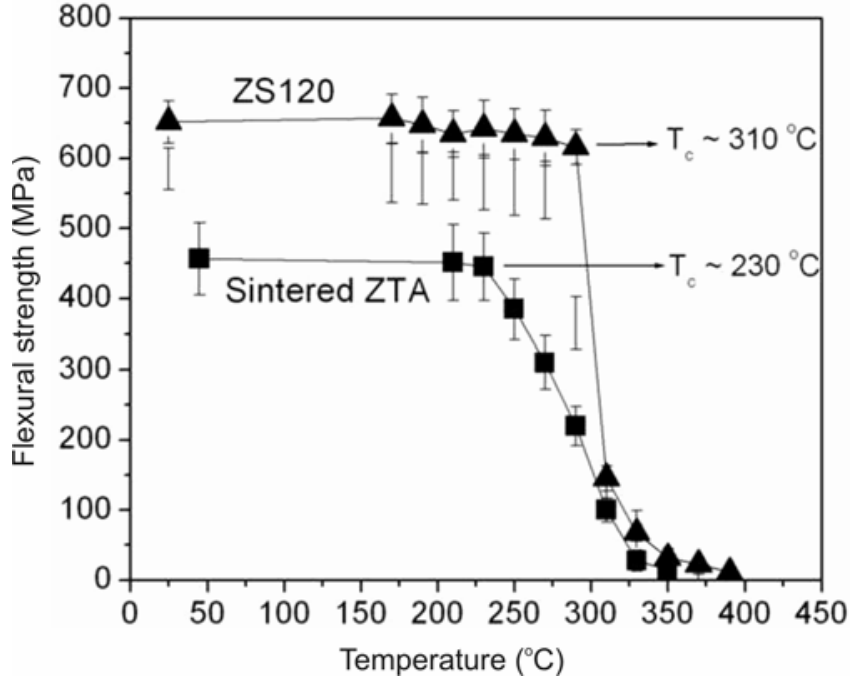

Figure 7. Variation of flexural strength as a function of quenching temperature.

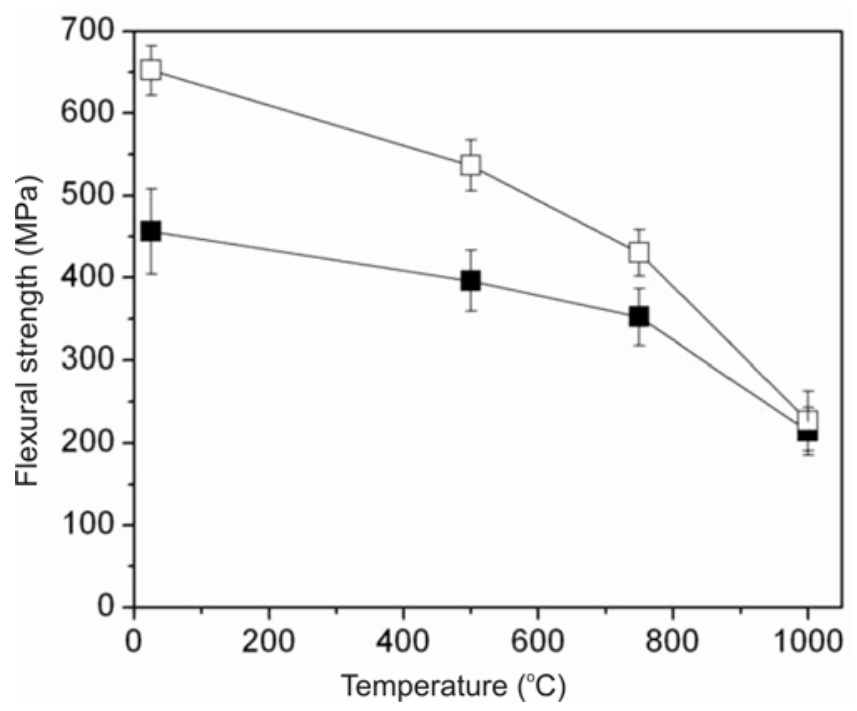

Figure 8. Flexural strength as a function of temperature.

stress down to a significant depth (over the depth of strength controlling flaws). When the flexural strength was measured, the glass penetrated region was under tensile load. This region requires some extra force initially to neutralize pre-existing compressive stress, before the system actually undergoes tensile stress, hence more force is required to break. In addition, the spheroidization of grains preferably minimizes the stress concentration zones in glass treated samples.

It was expected that the glass with a lower thermal expansion would cause a compressive stress, whereas the higher thermal expansion glass would yield a tensile stress. Contrary to the expectations, the higher expansion glass (SL) also induced a compressive stress only. The stress generated in the sample depends on its interaction

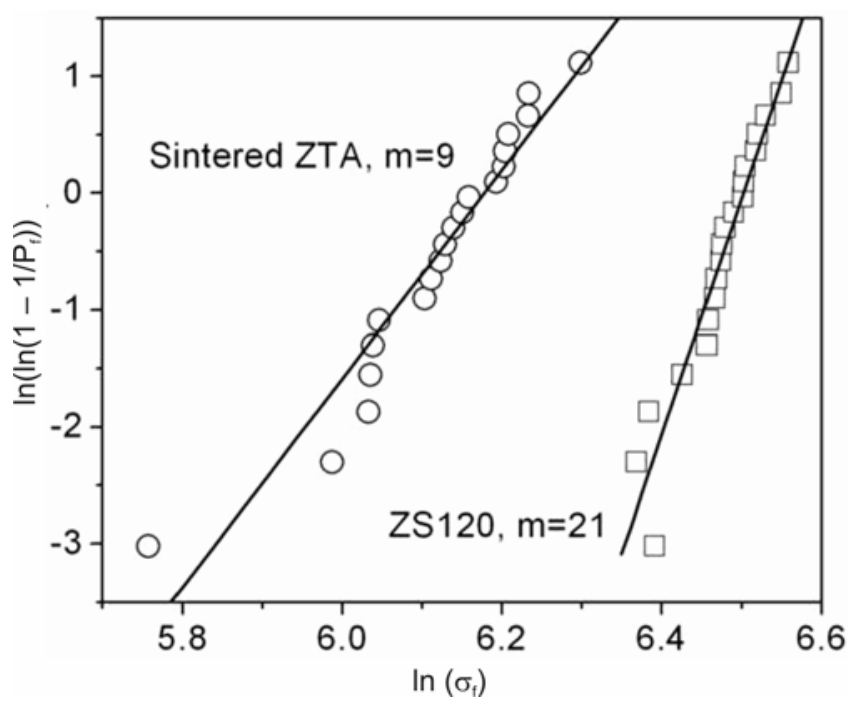

Figure 9. Plots used to determine the parameters of the Weibull distribution of room temperature strength. The values of Weibull modulus $(m)$ have also been shown.

with the glass and the final composition of the glass after penetration. In the present study, ZS120 sample showed better strength properties compared to ZTA sample. This process has an advantage over the other strengthening processes with respect to surface compression which can be introduced in components of complex shapes.

\section{Conclusions}

The penetrations of a high expansion SL glass successfully improved the flexural strength of ZTA by about $42 \%$ respectively by inducing compressive stresses. The compressive stress can be generated even by using the glass of high CTE value than the CTE of the matrix. Nature of the stress depends on the CTE of the penetrated glass but not on the CTE of initial glass. Glass penetration leads to removal of surface defects and flaws, thereby improving the reliability of the specimen. The magnitude of strength increment depends on the amount of the surface compressive stress. The glass treated specimens of ZTA-SL glass system exhibited superior strength and thermal shock resistance properties.

\section{References}

ASM International 1991 Engineered materials handbook: Ceramics and glasses (Ohio: ASM) p. 875

Balakrishnan A, Chu M C, Panigrahi B B, Yoon K J, Kim J C, Lee B C, Kim T N and Cho S J 2007 Solid State Phenom. 124-126 695

Chakraverty J P and Rice R W 1997 J. Mater. Sci. Lett. 16404 Chu M C, Panigrahi B B, Balakrishnan A, Yoon K J, Kim T N, Cho S J and Lee K H 2007 Mater. Sci. \& Eng. A452-453 110 Guazzato M, Albakry M, Linda Q and Swain M V 2005 Dent. Mater. 21454 
Goldstein J, Newbury D, Joy D, Lyman C, Echlin P, Lifshin E, Sawyer L and Michael J 2003 Scanning electron microscopy and $X$-ray microanalysis (New York: Springer) p. 286

Hua X K, Qiang Y and Xue Z Z 2003 West China J. STOMAT. 21238

ISO 147042000 Fine ceramics-Test method for flexural strength of monolithic ceramics at room temperature (Geneva, Switzerland: International Organization for Standardization)

Kirchner H P 1979 Strengthening of ceramics, treatments, tests and design applications (New York: Marcel Dekker)

Kirchner H P, Gruver R M and Walker R E 1968 J. Am. Ceram. Soc. 51251

Kirchner H P, Walker R E and Platts D R 1971 J. Appl. Phys. 423685

Kishino J, Nishiyama A and Sakuma T 1996 J. Mater. Sci. 31 4991

Lange F F 1982 J. Mater. Sci. 17235

Lin G -Y and Virkar A V 2001 J. Am. Ceram. Soc. 841321

Lin G Y, Lei T C, Zhou Y and Wang S X 1993 J. Mater. Sci. 28 2745

Marple B R and Green D J 1988 J. Am. Ceram. Soc. 71 C471

Magdalena S and Marek B 2006 J. Mater. Proc. Tech. 175 416

Marshall D B and Lawn B R 1977 J. Am. Ceram. Soc. 6086
Park H H, Kang S J and Yoon D N 1986 Metall. Trans. A17 325

Ramamurthy S, Mallamaci M P, Zimmerman C M, Carter C B, Duncombe P R and Shaw T M 1996 JMSA 2113

Swain M V 1980 J. Mater. Sci. Lett. 151577

Swain M V, Hagan J T and Fields J E 1977 J. Mater. Sci. Lett. 121914

Tandon R, Green D J and Cook R F 1977 J. Am. Ceram. Soc. 6086

Van-Acker K, De Buyser L, Celis J P and Van Houtte P 1994 J. Appl. Cryst. 2756

Virkar A V 1987 US Patent 465607

Virkar A V 1990 J. Am. Ceram. Soc. 732100

Virkar A V, Huang J L and Cutler R A 1987 J. Am. Ceram. Soc. 70164

Volf M B 1988 Mathematical approach to glass (New York: Elsevier) p. 208

Wulf P and Rombach M 1999 JCPDS-International Centre for Diffraction Data 493

Wulf P and Tobias F 2002 Berichte der Deutschen Keramischen Gesellschaft 79 E25-E28/ISSN 0173

Wulf P and Tobias F 2006 J. Eur. Ceram. Soc. 262639

Xiang J S, Hui X, Zhi-H J and Yong-L W 2004 Mater. Lett. 58 1750 